\title{
Erratum to: Signal detection theory and vestibular perception: II. Fitting perceptual thresholds as a function of frequency
}

\author{
Koeun Lim • Daniel M. Merfeld
}

Published online: 9 November 2012

(c) Springer-Verlag Berlin Heidelberg 2012

Erratum to: Exp Brain Res (2012) 222:303-320

DOI 10.1007/s00221-012-3217-2

It has been brought to the attention of the authors that they inadvertently included an incorrect citation in their paper. On pp. 307-308, the paper should have cited (Soyka, personal communication) instead of (Soyka et al. 2012) for the following statement: "The $\log$ can also be justified since for some cost functions this more evenly emphasizes all frequencies independent of whether the calculations are done using velocity, acceleration, or displacement as the input".

The online version of the original article can be found under doi:10.1007/s00221-012-3217-2.

K. Lim · D. M. Merfeld ( $\square)$

Massachusetts Eye and Ear Infirmary, Jenks Vestibular

Physiology Lab, 243 Charles St. Suite 421, Boston, MA, USA

e-mail: dan_merfeld@meei.harvard.edu

K. Lim

e-mail: koeunlim@mit.edu

D. M. Merfeld

Harvard Medical School, Otology and Laryngology,

Boston, MA, USA 